\title{
Estrogen receptor- $ß$ expression in human laryngeal carcinoma: Correlation with the expression of epithelial-mesenchymal transition specific biomarkers
}

\author{
ANASTASIOS K. GOULIOUMIS ${ }^{1,4}$, JONAS FUXE ${ }^{4,5}$, JOHN VARAKIS ${ }^{1}$, MARIA REPANTI ${ }^{3}$, \\ PANOS GOUMAS $^{2}$ and HELEN PAPADAKI ${ }^{1}$ \\ Departments of ${ }^{1}$ Anatomy, and ${ }^{2}$ Otorhinolaryngology-Head and Neck Surgery, School of Medicine, \\ University of Patras, Patras; ${ }^{3}$ Department of Pathology, 'Agios Andreas' General Hospital of Patras, Greece; \\ ${ }^{4}$ Department of Cell and Molecular Biology, Karolinska Institute, Stockholm, Sweden
}

Received April 21, 2009; Accepted June 17, 2009

DOI: 10.3892/or_00000537

\begin{abstract}
Laryngeal carcinoma is a malignancy of the respiratory tract with a significantly higher male to female ratio, suggesting involvement of gender-depended factors in the pathogenesis. Estrogen influences the pathological processes of hormone-dependent cancers, such as breast, prostate and ovarian cancers, through its receptors, estrogen receptor- $\alpha($ ER- $\alpha)$ and $-\beta($ ER- $\beta)$. While ER- $\alpha$ promotes cell proliferation, recent studies indicate that ER- $\beta$ is protective against carcinoma progression into an invasive state. However, it is unclear whether ER-ß plays a role in laryngeal cancer. In the present study we examined the expression of ER- $\beta$ in 80 invasive human squamous laryngeal carcinomas by immunohistochemistry and correlated ER- $\beta$ expression with markers of epithelial-mesenchymal transition (EMT). ER- $\beta$ was expressed in $83 \%$ of tumour specimens where it was localized in the nuclei of tumour cells. The expression of ER- $B$ correlated positively with the maintenance of Ecadherin and $\beta$-catenin at cell junctions and negatively with the loss of E-cadherin, nuclear translocation of $\beta$-catenin and increased TNM stage. We concluded that estrogen receptor- $\beta$ expression is documented in laryngeal cancer indicating a possible role in the pathogenesis of this malignancy. It is suggested that ER- $\beta$ could protect tumour cells from acquiring aggressive EMT features such as E-cadherin downregulation and nuclear ß-catenin activation.
\end{abstract}

Correspondence to: Dr John Varakis, Department of Anatomy, School of Medicine, University of Patras, Patras 26500, Greece E-mail: goulioum@upatras.gr

${ }^{5}$ Present address: Department of Medical Biochemistry and Biophysics, Karolinska Institute, Stockholm, Sweden

Key words: estrogen receptor- $\beta$ (ER- $\beta)$, E-cadherin, $\beta$-catenin, vimentin, laryngeal carcinoma

\section{Introduction}

Laryngeal carcinoma represents the second most frequent malignancy of the respiratory apparatus, secondary to pulmonary carcinoma with a 7:1 male to female ratio (1). It is interesting that the difference in susceptibility to laryngeal cancer based on gender has remained unchanged through the years in spite of the increasing tobacco and alcohol consumption among women (2), suggesting the involvement of gender-dependent factors in the pathogenesis. Sex hormones like estrogens play significant roles in the pathogenesis of several malignancies including mammary carcinomas (3). The larynx represents another site in the body, which is influenced by sex hormones during puberty (4), suggesting that these hormones could also be involved in the pathogenesis of laryngeal cancer.

Estrogens are steroids functioning through nuclear receptors, which act as ligand dependent transcription factors $(5,6)$. Prior to ligand binding, the estrogen receptors (ER) are kept inactive in the cytoplasm through association with heat shock proteins precluding them from DNA binding. Ligand binding releases the inhibitory heat shock proteins, and the receptor rapidly translocates to the nucleus, where it binds DNA as a homodimer on estrogen responsive elements within the regulatory regions of target genes that are implicated in the regulation of the cell cycle, cell adhesion and differentiation (7-9).

Estrogen plays a paradoxical role in human cancer as a promoter of carcinoma progression in some cases and an inhibitor of cancer cell invasion in others $(6,10,11)$. This may be explained by recent findings indicating that the estrogen receptors (ER), ER- $\alpha$ and ER- $\beta$, have opposite effects in the pathogenesis of cancer $(7,8)$. Functional studies have indicated that in breast and gynaecological cancer cells, activation of ER- $\alpha$ is associated with tumour cell proliferation and growth (12). In contrast, expression of ER- $\beta$ promotes apoptosis, suppresses malignant transformation and inhibits tumour cell growth (13). Thus, ER- $\alpha$ acts as a tumour promoter and ER- $\beta$ as a tumour suppressor. This concept is in agreement with clinical evaluations showing that ER- $\beta$ expression in breast, ovarian and colon tumours is associated 
with better prognosis (14-16). The role of ER- $\beta$ in laryngeal cancer is unknown.

The epithelial-mesenchymal transition (EMT) is an essential process for normal development and is implicated in carcinoma progression into an invasive state (17). EMT can be induced by cytokines, such as Wnt and TGF-B (18) and is characterized by loss of E-cadherin at cell junctions, nuclear translocation of $\beta$-catenin and transcription factors like SNAIL1 and SMADs (19), increased expression of vimentin and other mesenchymal markers (20), cellular elongation and enhanced migratory capacity (17). Downregulation of E-cadherin and nuclear activation of B-catenin represent key molecular events in the progression of several human malignancies $(21,22)$, including laryngeal cancer $(23,24)$. ER- $\alpha$ is implicated in the loss of E-cadherin in tumour cells while ER- $\beta$ inhibits downregulation of E-cadherin induced by ER- $\alpha(25)$.

Based on the dominant male-female incidence ratio of laryngeal carcinoma, the fact that larynx is a target organ for estrogen and the protective role of ER- $\beta$ in breast and ovarian cancer, we hypothesized that ER- $\beta$ signalling could play a protective role in laryngeal carcinomas. The expression of ER- $\beta$ was studied by immunohistochemistry in a series of 80 invasive human laryngeal squamous cell carcinomas and correlated with the invasive properties of the tumours, as measured by the expression and localization of EMT markers and TNM stage classification.

\section{Materials and methods}

Tissue specimens. The study was performed in accordance with the institutional ethical guidelines and has been approved by the Committee on Research and Ethics and the Scientific Committee of the University Hospital of Patras, Greece. Formalin-fixed, paraffin-embedded tissue samples from 80 primary human invasive squamous laryngeal carcinomas were obtained from the Department of Pathology, Agios Andreas General Hospital, Patras, Greece. Adjacent nonneoplastic laryngeal tissue was used as control. Our material was randomly selected from 80 patients (2 women and 78 men). Ages ranged from 40 to 86 years, with an average age of 60 years. The WHO classification (26) of tumours was used to determine the histological grade: 20/80 tumours (25\%) were classified as grade I, 31/80 (37.3\%) as grade II and $29 / 80(36.2 \%)$ as grade III. Twenty-eight out of $80(35 \%)$ tumours were stage I, 20/80 (25\%) stage II, 13/80 (15.7\%) stage III and 19/80 (22.9\%) stage IV A according to TNM staging.

Immunohistochemistry. Representative 4- $\mu \mathrm{m}$ tissue sections were dewaxed in xylene and rehydrated in graded ethanols. Antigen retrieval was enhanced by microwaving the slides in $0.01 \mathrm{M}$ citrate buffer ( $\mathrm{pH}$ 6.0). Endogenous peroxidase activity was quenched by treatment with $1 \%$ hydrogen peroxide for $25 \mathrm{~min}$, followed by incubation with protein blocking solution. Sections were subsequently incubated with anti-ER- $\beta$ (rabbit polyclonal, Biogenex, prediluted), for $1 \mathrm{~h}$ in room temperature and mouse anti- $\beta$-catenin (BD Biosciences, CA, USA, dilution 1:2000), mouse anti-Ecadherin (BD Biosciences, dilution 1:2000) and vimentin
(Novocastra, UK, dilution 1:120) overnight at $4^{\circ} \mathrm{C}$. Bound primary antibody was detected using the biotin-streptavidinperoxidase method (Envision Detection Kit, Dako, Hamburg, Germany) and visualized using diaminobenzidine as the chromogen. Slides were counterstained with haematoxylin, dehydrated and mounted. For negative controls, blocking solution was added instead of the primary antibody. As positive controls, human prostate carcinoma tissue was used.

Immunohistochemical evaluation. All slides were assessed by one pathologist (H.P.) and one investigator (A.G.) independently and blinded to the case. For the nuclear expression of ER- $\beta$ both intensity of staining and percentage of positive cells were taken into account and the following scoring system was used: 0 , no staining or weak staining in $<10 \%$ of tumour cells; 1 , weak staining in $10-40 \%$ of tumour cells or moderate staining in $<40 \%$ of tumour cells; 2 , weak staining in $>70 \%$ of cells, moderate staining in $40-70 \%$ of tumour cells or strong staining in $10-40 \%$ of tumour cells; and 3 , moderate staining in $>70 \%$ or strong staining in $>40 \%$ of tumour cells. Cases with score 0 were considered negative and cases with scores 1, 2 or 3 were considered positive. Cytoplasmic staining of $\beta$-catenin as well as membranous staining of $\beta$-catenin was homogeneously distributed among tumour cells and it was scored based on the intensity of staining as follows; score 0 , negative staining; 1 , weak staining; 2, moderate staining; and 3, strong staining. In all cases negative staining corresponds to complete absence of staining, strong corresponds to staining that can be easily recognized with light microscope at magnification (x4), weak corresponds to staining that can be recognized only at magnification (x20) and moderate is the staining with intensity values intermediate of weak and strong. Nuclear expression of $\beta$-catenin, cytoplasmic expression of vimentin and membranous expression of E-cadherin showed no significant variations in intensity of staining and the following scoring system was applied based on the percentage of positive cells: score 0 , staining in $<10 \%$ of tumour cells; 1 , staining in $10-40 \%$ of tumour cells; score 2 , staining in $40-70 \%$ of tumour cells; and score 3, staining in $>70 \%$ of tumour cells. Cases with score 0 were considered negative and cases with scores 1,2 or 3 were considered positive. In case of cytoplasmic $\beta$-catenin increased cytoplasmic expression was defined as score $>1$ since in adjacent non-neoplastic laryngeal mucosa expression of cytoplasmic $\beta$-catenin had a score 1 . In case of membranous $\beta$-catenin and membranous E-cadherin decreased membranous expression was defined as score $<3$ since adjacent non-neoplastic laryngeal mucosa had a score 3 for membranous localization of both proteins.

Statistical analysis. Statistical analysis was performed with the SPSS for Windows, release 15.0 (SPSS Inc., Chicago, IL, USA). Correlations of protein expression levels with clinicopathological parameters were analyzed with the nonparametric Kruskal-Wallis or Mann-Whitney tests for ordinal data and $\chi^{2}$ test for nominal data. Correlations between expression of proteins (immunohistochemical scores) were evaluated by the Spearman rank-order correlation coefficient. Parametric tests were performed with correction for ties. The significance level was defined as $\mathrm{p}<0.05$. 

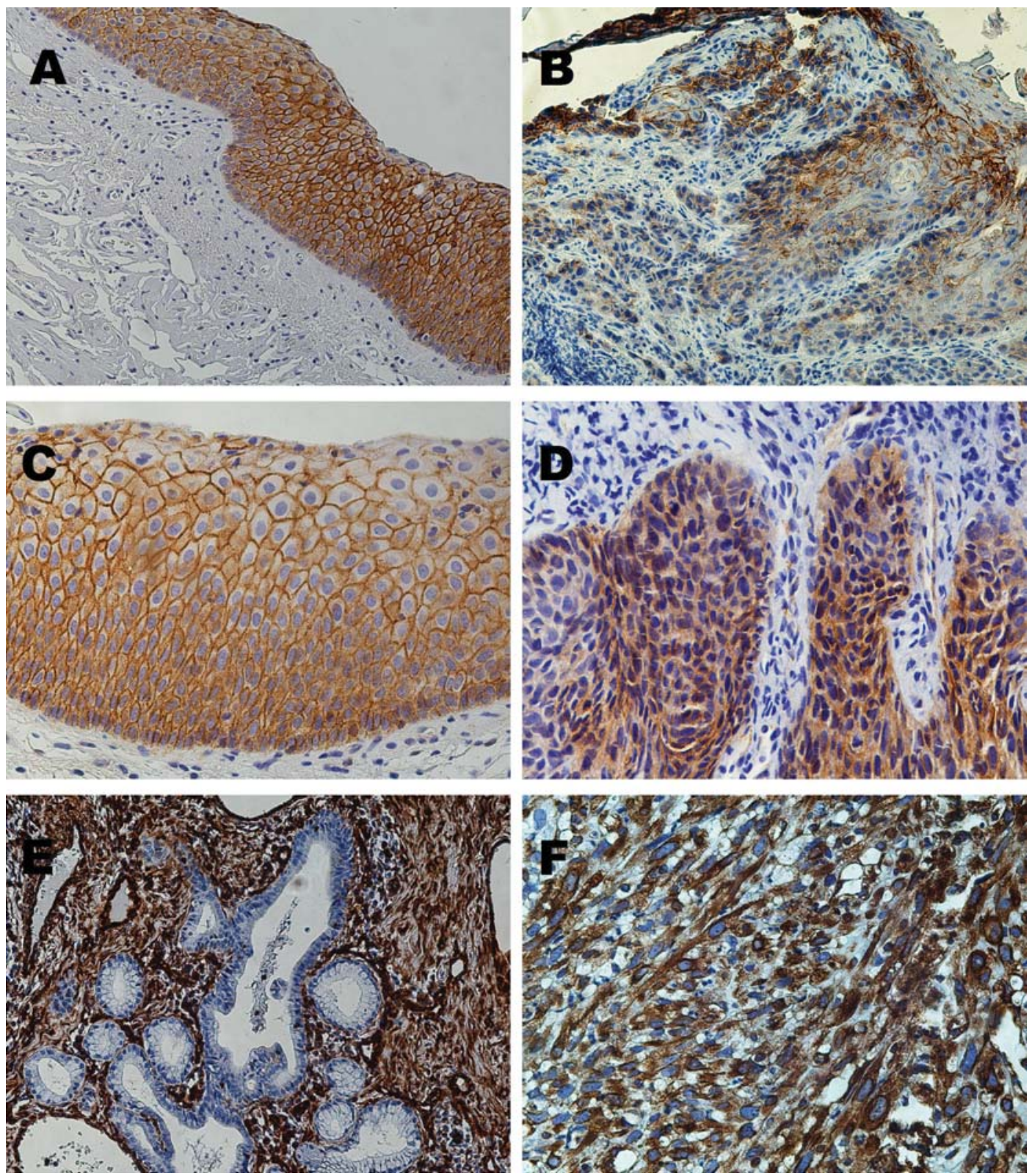

Figure 1. Adjacent non-neoplastic laryngeal mucosa: membranous staining of E-cadherin (A) (x200), B-catenin (C) (x400) and negative immunostaining for vimentin in the epithelial component (E) (x200). Laryngeal squamous carcinoma: loss of membranous E-cadherin (B) (x200), cytoplasmic and nuclear staining for ß-catenin (D), cytoplasmic staining for vimentin (F) (x400).

\section{Results}

Expression of E-cadherin, $\beta$-catenin and vimentin in laryngeal carcinoma. Expression of E-cadherin was evaluated in 80 laryngeal carcinomas and adjacent normal tissue. Normal epithelial cells of adjacent non-neoplastic tissue showed continuous membranous staining (score 3 ). Reduced expression of E-cadherin (score $<3$ ) was detected in 59 of 80 tumours $(73.8 \%)$ examined. Cytoplasmic expression of E-cadherin was detected in $15 \%$ of the cases. Immunohistochemical analysis of $ß$-catenin protein expression in 80 laryngeal carcinomas revealed nuclear localization (score $>0$ ), cytoplasmic pooling (score $>1$ ) or diminished membrane expression (score $<3$ ) of $\beta$-catenin in 41.2, 76.2 and $77.5 \%$, of cases, respectively. Adjacent normal mucosa showed strong membranous (score 3 ) or weak cytoplasmic (score 1) ß-catenin localization. Finally, expression of vimentin was evaluated in 80 laryngeal carcinomas and adjacent nonneoplastic tissue. Normal epithelial cells of adjacent nonneoplastic tissue showed negative staining for vimentin. Expression of vimentin was detected in 35 of 80 tumours $(45.8 \%)$ examined and vimentin immunoreactivity was confined to the cytoplasm of cancer cells. In $22.9 \%$ of cases vimentin expression was weak while moderate and strong immunostaining was found in 14.5 and $4.8 \%$ of tumours, respectively (Fig. 1).

Estrogen receptor $-\beta$ is overexpressed in laryngeal carcinomas. Expression of ER- $\beta$ was evaluated in 80 laryngeal carcinomas and adjacent non-neoplastic laryngeal tissue. Normal epithelial cells of adjacent non-neoplastic tissue showed negative staining for ER- $\beta$. Expression of ER- $\beta$ was detected in 67 of 80 tumours $(83.8 \%)$ examined and ER- $\beta$ immunoreactivity was confined to the nucleus of 

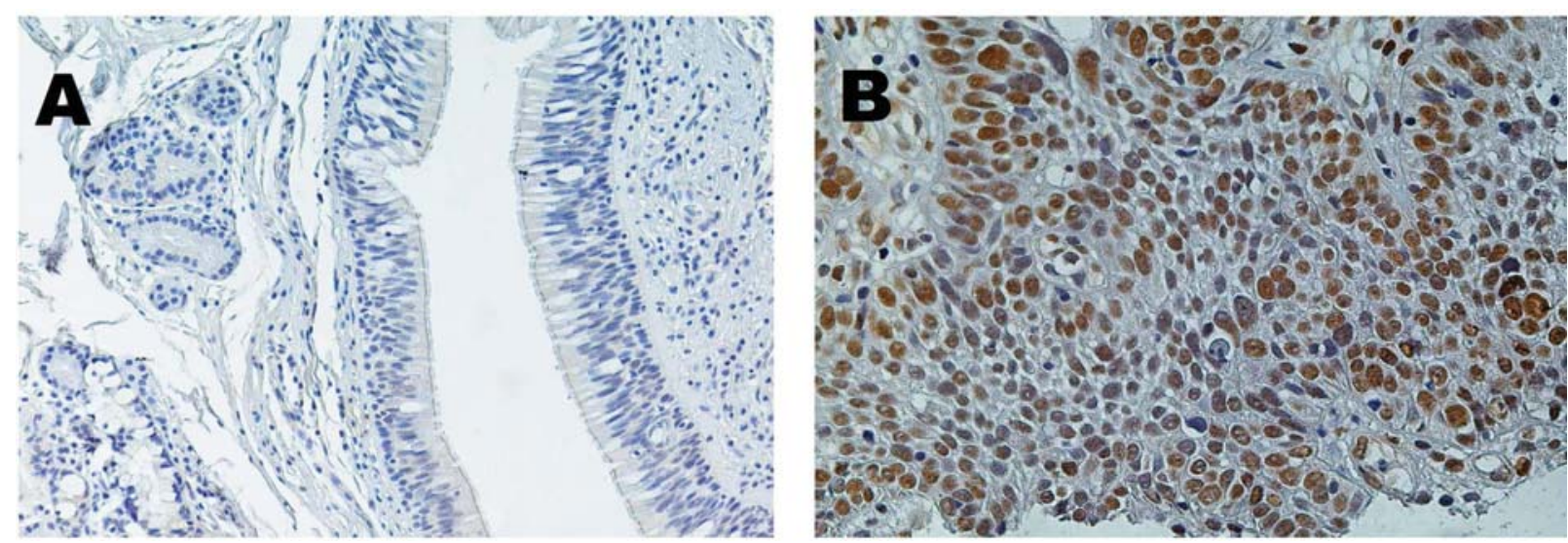

Figure 2. Non-neoplastic laryngeal tissue without ER-ß expression (x200) (A). Nuclear expression of ER-ß in laryngeal carcinoma (x400) (B).

Table I. Estrogen receptor- $ß$ expression in laryngeal carcinoma.

\begin{tabular}{|c|c|c|c|c|c|c|}
\hline & \multirow[b]{3}{*}{$\mathrm{N}$} & \multicolumn{4}{|c|}{ Nuclear estrogen receptor- $\beta^{a}$} & \multirow[b]{3}{*}{ P-value } \\
\hline & & 0 & 1 & 2 & 3 & \\
\hline & & $\mathrm{n}(\%)$ & $\mathrm{n}(\%)$ & $\mathrm{n}(\%)$ & $\mathrm{n}(\%)$ & \\
\hline \multicolumn{7}{|l|}{ Carcinomas } \\
\hline Total & 80 & $13(16.2)$ & $12(15)$ & $22(27.5)$ & $33(41.2)$ & \\
\hline Grade & & & & & & 0.142 \\
\hline I & 20 & $3(15)$ & $2(10)$ & $5(25)$ & $10(50)$ & \\
\hline II & 31 & $3(9.7)$ & $5(16.1)$ & $8(25.8)$ & $15(48.4)$ & \\
\hline III & 29 & $7(24.1)$ & $5(17.2)$ & $9(31)$ & $8(27.6)$ & \\
\hline TNM stage & & & & & & 0.021 \\
\hline I & 28 & $1(3.6)$ & $3(10.7)$ & $7(25)$ & $17(60.7)$ & \\
\hline II & 20 & $5(25)$ & $2(10)$ & $8(40)$ & $5(25)$ & \\
\hline III & 13 & $2(15.4)$ & $3(23.1)$ & $2(15.4)$ & $6(46.1)$ & \\
\hline IV & 19 & $5(26.3)$ & $4(21.1)$ & $5(26.3)$ & $5(26.3)$ & \\
\hline
\end{tabular}

Correlation with clinicopathological parameters. ${ }^{a}$ ER- $\beta$ expression was scored as described in Materials and methods. ${ }^{b}$ Kruskal-Wallis or Mann-Whitney test; $\mathrm{p}<0.05$ was considered statistically significant.

cancer cells (Fig. 2). A few tumours showed weak cytoplasmic staining of ER- $\beta$. In $15 \%$ of cases ER- $\beta$ expression was weak while moderate and strong immunostaining was found in 27.5 and $41.2 \%$ of tumours, respectively. Statistical analysis showed a reverse correlation between ER- $\beta$ expression and TNM stage $(\mathrm{p}=0.021)$ (Table I).

Expression of estrogen receptor- $\beta$ correlates positively with the maintenance of E-cadherin and $\beta$-catenin in the membrane and negatively with activation of $\beta$-catenin. In the 80 cases of laryngeal carcinomas examined in the present study, expression of ER- $\beta$ was correlated significantly with membranous $\beta$-catenin staining $(\mathrm{r}=0.299, \mathrm{p}=0.007)$ while nuclear accumulation of $\beta$-catenin was negatively correlated with ER- $\beta$ expression ( $\mathrm{r}=-0.328, \mathrm{p}=0.003$ ). Moreover, there was a positive correlation between the expression of ER- $\beta$ and the expression of E-cadherin in cell membrane $(r=0.312$, $\mathrm{p}=0.005$ ) and finally no correlation was reported between ER- $\beta$ and vimentin expression.

\section{Discussion}

Laryngeal cancer is a malignancy of male prevalence, a fact reflected in our study where female patients accounted for just $2.5 \%$. This suggests the involvement of gender-related factors, such as hormone receptor signalling, in the pathogenesis of laryngeal carcinoma. Estrogen receptors function as transcription factors and play a role in the progression of several human malignancies. Although the expression of steroid receptors was controversial in laryngeal carcinoma (27), our results confirmed recent data showing ER- $\beta$ expression in laryngeal cancer (28). 
The results from our study showed that the expression of ER- $\beta$ correlated positively with the expression of $\beta$-catenin in the cell membrane $(r=0.299, p=0.007)$ and negatively with the translocation of $B$-catenin to the nucleus $(\mathrm{r}=-0.328$, $\mathrm{p}=0.003$ ). Together with previous studies showing that ERs can act as co-factors for $\beta$-catenin/LEF transcription factors (29) and regulate the expression of factors related to the Wnt pathway (30), this implies crosstalk between ER signalling and the Wnt/ß-catenin pathway.

Furthermore, our results showed a significant correlation between the expression of ER- $\beta$ and the maintenance of E-cadherin at the plasma membrane in tumour cells ( $\mathrm{r}=0.312$, $\mathrm{p}=0.005)$, similarly to that shown in ovarian carcinoma (31). Loss of E-cadherin is a characteristic feature in many forms of human cancer and correlates with tumour cell invasion and activation of EMT markers. This indicates that ER- $\beta$ signalling might protect against the induction of EMT during malignant progression into an invasive state. In support of this, the expression of ER- $\beta$ significantly correlated with tumours of early TNM stage $(p=0.021)$ indicating that ER- $\beta$ might be used as a prognostic marker in laryngeal carcinoma. However, it remains to be studied whether ER- $\beta$ expression also correlates with increased survival. ER- $\beta$ may be implicated in the molecular mechanisms that preserve E-cadherin and $\beta$-catenin in the membrane, avoiding at the same time $\beta$-catenin activation in the nucleus, which initiates a plethora of molecular phenomena related to the enhancement of tumour cell aggressiveness (22). In line with this, recent studies indicate that an ER- $\beta$ agonist upregulates E-cadherin and attenuates $\beta$-catenin signalling in mammary epithelial cells (32). A possible favourable prognosis of ER-B, similar to breast cancer (14) and ovarian carcinoma (15), due to a yet unknown protective action of these receptors in laryngeal carcinoma, have been reported.

The expression of ER- $\beta$ did not significantly correlate with vimentin expression. This may imply that the possible role of ER- $\beta$ during EMT may be more related to the preservation of epithelial character than to preventing mesenchymal characteristics, a fact also reflected by the lack of literature showing correlation between ER- $\beta$ and mesenchymal markers.

In conclusion, we documented estrogen receptor- $\beta$, expression in laryngeal cancer suggesting a possible role in the pathogenesis of this malignancy. The expression of ER- $\beta$ correlated with early stage tumours suggesting that ER- $\beta$ could protect tumour cells from acquiring aggressive features such as E-cadherin downregulation and nuclear $B$-catenin activation. In agreement with these results, ER- $\beta$ agonists, phytoestrogens, have been found to act as chemopreventive agents in various carcinomas $(33,34)$.

\section{References}

1. Parkin DM, Bray F, Ferlay J and Pisani P: Global cancer statistics, 2002. CA Cancer J Clin 55: 74-108, 2005.

2. Gu D, Kelly TN, Wu X, et al: Mortality attributable to smoking in China. NEJM 360: 150-159, 2009.

3. Planas-Silva MD and Waltz PK: Estrogen promotes reversible epithelial to mesenchymal like transition and collective motility in MCF-7 breast cancer cells. J Ster Biochem Mol Biol 104 211-217, 2007

4. Fuchs M: Landmarks of physiological development of the voice in childhood and adolescence (part 1). Laryngorhinootologie 87: 10-16, 2008
5. Yamashita S: Localization and functions of steroid hormone receptors. Histol Histopathol 13: 255-270, 1998.

6. Heldring N, Pike A, Andersson S, et al: Estrogen receptors: how do they signal and what are their targets. Physiol Rev 87: 905-931, 2007

7. Liu MM, Albanese C, Anderson CM, et al: Opposing action of estrogen receptors $\alpha$ and $B$ on cyclin D1 gene expression. J Biol Chem 277: 24352-24360, 2002.

8. Helguero LA, Lindberg K, Gardmo C, Schwend T, Gustafsson JA and Haldosén LA: Different roles of estrogen receptors A and $\mathrm{B}$ in the regulation of E-cadherin protein levels in a mouse mammary epithelial cell line. Cancer Res 68: 8695-8704, 2008.

9. Prins GS and Korach KS: The role of estrogens and estrogen receptors in normal prostate growth and disease. Steroids 73: 233-244, 2008

10. Di Leo A, Cavallini A and Linsalata M: Estrogens and colorectal cancer. Curr Drug Targets Immune Endocr Metabol Disord 1: 1-12, 2001.

11. Ho SM, Leung YK and Chung I: Estrogens and antiestrogens as etiological factors and therapeutics for prostate cancer. Ann NY Acad Sci 1089: 177-193, 2006.

12. Ali S and Coombes RC: Estrogen receptor alpha in human breast cancer: occurrence and significance. J Mammary Gland Biol Neoplasia 5: 271-281, 2000.

13. Koehler KF, Helguero LA and Haldosén LA: Reflections on the discovery and significance of estrogen receptor beta. Endocr Rev 26: 465-478, 2005.

14. Järvinen TA, Pelto-Huikko M, Holli K and Isola J: Estrogen receptor beta is coexpressed with ERalpha and PR and associated with nodal status, grade, and proliferation rate in breast cancer. Am J Pathol 156: 29-35, 2000.

15. Lazennec G: Estrogen receptor, a possible tumor suppressor involved in ovarian carcinogenesis. Cancer Lett 231: 151-157, 2006.

16. Konstantinopoulos PA, Kominea A, Vandoros G, et al: Oestrogen receptor beta (ERß) is abundantly expressed in normal colonic mucosa, but declines in colon adenocarcinoma paralleling the tumour's dedifferentiation. Eur J Cancer 39: 1251-1258, 2003.

17. Wu Y and Zhou BP: New insights of epithelial-mesenchymal transition in cancer metastasis. Acta Biochim Biophys Sin 40: 643-650, 2008.

18. Moustakas A and Heldin $\mathrm{CH}$ : Signaling networks guiding epithelial-mesenchymal transitions during embryogenesis and cancer progression. Cancer Sci 98: 1512-1520, 2007.

19. Medici D, Hay ED and Goodenough DA: Cooperation between snail and LEF-1 transcription factors is essential for TGF-beta1induced epithelial-mesenchymal transition. Mol Biol Cell 17: 1871-1879, 2006

20. Kokkinos MI, Wafai R, Wong MK, Newgreen DF, Thompson EW and Waltham M: Vimentin and epithelial-mesenchymal transition in human breast cancer - observations in vitro and in vivo. Cells Tissues Organs 185: 191-203, 2007.

21. Schmalhofer O, Brabletz S and Brabletz T: E-cadherin, B-catenin, and ZEB1 in malignant progression of cancer. Cancer Metastasis Rev 1-2: 151-166, 2009.

22. Smalley MJ and Dale TC: Wnt signalling in mammalian development and cancer. Cancer Metastasis Rev 18: 215-230, 1999.

23. Lopez-Gonzalez JS, Cristerna-Sanchez L, VazquezManriquez ME, Jimenez-Orci G and Aguilar-Cazares D: Localization and level of expression of $\beta$-catenin in human laryngeal squamous cell carcinoma. Otolaryngol Head Neck Surg 1: 89-93, 2004.

24. Rodrigo JP, Dominguez F, Suárez V, Canel M, Secades P and Chiara MD: Focal adhesion kinase and E-cadherin as markers for nodal metastasis in laryngeal cancer. Arch Otolaryngol Head Neck Surg 133: 145-150, 2007

25. Park SH, Cheung LW, Wong AS and Leung PC: Estrogen regulates Snail and Slug in the downregulation of E-cadherin and induces metastatic potential of ovarian cancer cells through estrogen receptor alpha. Mol Endocrinol 22: 2085-2098, 2008.

26. Cardesa A, Gale N, Nadal A, et al: Squamous cell carcinoma. In: World Health Organization Classification of Tumors, Pathology and Genetics of Head and Neck Tumors. L Barnes (ed). IARC Press, Lyon, pp118-121, 2005.

27. Hagedorn HG and Nerlich AG: Analysis of sex-hormone-receptor expression in laryngeal carcinoma. Eur Arch Otorhinolaryngol 259: $205-210,2002$ 
28. Lukits J, Remenár E, Rásó E, Ladányi A, Kásler M and Tímár J: Molecular identification, expression and prognostic role of estrogen- and progesterone receptors in head and neck cancer. Int J Oncol 30: 155-160, 2007.

29. Mulholland DJ, Dedhar S, Goetzee GA and Nelson CC: Interaction of nuclear receptors with the $\mathrm{Wnt} / \mathrm{B}$-catenin/Tcf signaling axis: Wnt You Like to Know? Endocr Rev 26: 898$915,2005$.

30. Hou X, Tan Y, Li M, Dey SK and Das SK: Canonical Wn signaling is critical to estrogen mediated uterine growth. Mol Endocrinol 18: 3035-3048, 2004.

31. Ding JX, Feng YJ, Yao LQ, Yu M, Jin HY and Yin LH: The reinforcement of invasion in epithelial ovarian cancer cells by 17 beta-Estradiol is associated with up-regulation of Snail. Int J Oncol 30: 1069-1075, 2006
32. Su Y and Simmen RCM: Soy isoflavone Genistein up-regulates epithelial adhesion molecule E-cadherin expression and attenuates $B$-catenin signaling in mammary epithelial cells. Carcinogenesis 30: 331-339, 2008

33. Syed DN, Khan N, Afaq F and Mukhtar H: Chemoprevation of prostate cancer through dietary agents: progress and promise. Cancer Epidemiol Biomarkers Prev 16: 193-203, 2007.

34. Le Corre L, Chalabi N, Delort L, Bignon YJ and BernardGallon DJ: Resveratrol and breast cancer chemoprevention: molecular mechanisms. Mol Nutr Food Res 49: 462-471, 2005. 